\title{
Accession Site Does Not Influence the Risk of Stroke after Diagnostic Coronary Angiography or Intervention: Results from a Large Prospective Registry
}

\author{
Jan Matějka a,b, c Ivo Varvařovskýd Jan Tužile, fomáš Doležale, $g$

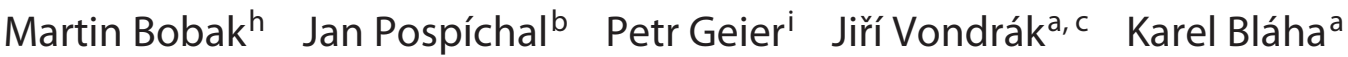

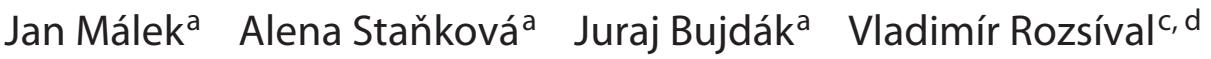 \\ Vojtěch Novotnýd ${ }^{d}$ Tomáš Lazarák ${ }^{d}$ Milan Plíva $^{d}$ Jan Večeřad Petr Vojtíšek ${ }^{a}$

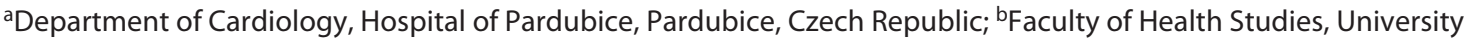

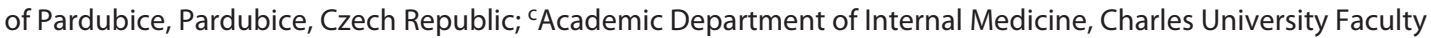 \\ of Medicine, Hradec Králové, Czech Republic; 'Department of Invasive Cardiology, Cardiology Center AGEL,

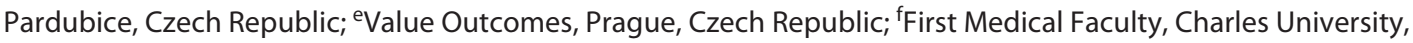 \\ Prague, Czech Republic; '9Department of Pharmacology, Faculty of Medicine, Masaryk University, Brno, Czech \\ Republic; ' Department of Epidemiology and Public Health, University College London, London, UK; 'Department of \\ Neurology, Hospital of Pardubice, Pardubice, Czech Republic
}

\section{Keywords}

Stroke-Transient ischemic attack - Cardiac catheterization · Femoral access $\cdot$ Radial access

\begin{abstract}
Introduction: Periprocedural stroke represents a rare but serious complication of cardiac catheterization. Pooled data from randomized trials evaluating the risk of stroke following cardiac catheterization via transradial versus transfemoral access showed no difference. On the other hand, a significant difference in stroke rates favoring transradial access was found in a recent meta-analysis of observational studies. Our aim was to determine if there is a difference in stroke risk after transradial versus transfemoral catheterization within a contemporary real-world registry. Methods: Data from 14,139 patients included in a single-center prospective reg-
\end{abstract}

istry between 2009 and 2016 were used to determine the odds of periprocedural transient ischemic attack (TIA) and stroke for radial versus femoral catheterization via multivariate logistic regression with Firth's correction. Results: A total of 10,931 patients underwent transradial and 3,208 underwent transfemoral catheterization. Periprocedural TIA/ stroke occurred in 41 (0.29\%) patients. Age was the only significant predictor of TIA/stroke in multivariate analysis, with each additional year representing an odds ratio $(O R)=1.09$ (CI 1.05-1.13, $p<0.000$ ). The choice of accession site had no impact on the risk of periprocedural TIA/stroke $(\mathrm{OR}=0.81 ; \mathrm{Cl}$ $0.38-1.72, p=0.577)$. Conclusion: Observational data from a large prospective registry indicate that accession site has no influence on the risk of periprocedural TIA/stroke after cardiac catheterization.

C 2021 The Author(s) Published by S. Karger AG, Basel karger@karger.com www.karger.com/cee

Karger $\stackrel{\text { ' }}{=}$ BOPEN ACCESS
(C) 2021 The Author(s)

Published by S. Karger AG, Basel

This is an Open Access article licensed under the Creative Commons Attribution-NonCommercial-4.0 International License (CC BY-NC) (http://www.karger.com/Services/OpenAccessLicense), applicable to the online version of the article only. Usage and distribution for commercial purposes requires written permission.
Correspondence to:

Jan Matějka, jan.matejka@nempk.cz 


\section{Introduction}

Stroke represents a major and potentially devastating complication of cardiac diagnostic and interventional catheterization procedures. Meta-analyses evaluating the risk of stroke following cardiac catheterization via transradial access (TRA) versus transfemoral access (TFA) showed no difference in pooled data from randomized trials (RT) [1-5]. A debate has continued for over 13 years on whether the choice of accession site increases the risk of periprocedural stroke [6-9]. The debate seemed settled until recently when a significantly lower risk was reported for radial catheterization in a Japanese registry [5]. However, such conclusions are not in line with observations from the European and American cohorts [6-9].

Our aim was to determine the odds of periprocedural transient ischemic attack (TIA)/stroke between patients undergoing cardiac catheterization via transradial versus transfemoral approach. The primary hypothesis was tested in the sample of consecutive patients undergoing cardiac catheterization in Pardubice Hospital between 2009 and 2016.

\section{Materials and Methods}

\section{Database Description}

In our database, the demographic, anthropometric, clinical, and procedural data of all consecutive patients undergoing elective cardiac catheterization were collected on a daily basis by the treating physicians. Data regarding procedural complications were cross-checked annually with our CathLab internal database. Records were matched with the National Health Information System (NZIS) database administered by the Institute of Health Information and Statistics of the Czech Republic (ÚZIS) using a unique patient identifier and date of procedure to provide long-term follow-up, notably 1-year mortality and 1-year revascularization.

\section{Inclusion Criteria/Study Population}

All elective invasive cardiac procedures performed at our institution between January 2009 and January 2016 were assessed for analysis, including diagnostic and/or interventional catheterization, first procedure or repeated procedure, and elective or acute catheterization. Records indicating ulnar, brachial, combined, or unspecified accession site were excluded.

\section{Endpoint Definition}

The principal endpoint was the occurrence of clinically overt stroke or TIA after cardiac catheterization within index hospitalization. All patients with suspected neurological complications were referred for clinical examination and computed tomography or magnetic resonance imaging scan. Final diagnosis and confirmation or exclusion of stroke/TIA was made by a neurological consultant. Stroke and TIA were defined as acute onset of a focal neurological deficit. Patients with transient focal neurological def- icit lasting $<24 \mathrm{~h}$ without acute ischemic lesions on magnetic resonance imaging were considered to have TIA. Patients with focal neurological deficit lasting $>24 \mathrm{~h}$ and/or positive findings on brain imaging were considered to have stroke. Ischemic stroke, intracerebral hemorrhage, and subarachnoidal hemorrhage were considered for analysis. Modified Rankin score (mRS) at 3 months after hospital discharge was used to assess the functional outcome of patients affected [10]. Cases of delirium, contrast-induced neurotoxicity, and other transient neurological symptoms not fulfilling the criteria for stroke were not included [11].

Neurological complications following subsequent urgent cardiac surgery procedures within index hospitalization were excluded.

\section{Cardiac Procedures}

Techniques of diagnostic coronary angiography, percutaneous coronary intervention (PCI), other interventions, concomitant medication, sheath removal, and vascular access closure management were left to the discretion of individual operators. Our institution's protocol for periprocedural antithrombotic therapy did not change during the study period. Unfractionated heparin at doses of 5,000 IU for transradial and 3,000 IU for transfemoral diagnostic procedures was used. Unfractionated heparin at doses $70-100 \mathrm{IU} / \mathrm{kg}$ according to generally accepted recommendations was used for PCI [12].

\section{Statistical Analysis}

The normality of baseline covariates was checked using the Shapiro-Wilk test. Differences between the transradial and transfemoral groups were tested at $\alpha=0.05$ using the $t$ test or 2-sided exact significance test. In the following models, we included firstorder covariates that (a) significantly differed between the groups or (b) were considered clinically relevant, such as age, gender, and calendar year of the intervention.

In the first step, we tested the impact of individual baseline parameters on the development of periprocedural stroke using multivariate logistic regression. Then, we calculated propensity score (PS) as the probability of being chosen for transradial catheterization based on the selected baseline parameters. The model specification was checked using the adjusted coefficient of determination, likelihood-ratio test, and plots showing PS distribution in each group. The primary hypothesis was tested using PS-adjusted logistic regression with Firth's correction for rare outcomes [13, 14]. To cross-check the hypothesis, we used PS-matching with 0.1 caliper width. Robust errors were used to correct for heteroscedasticity.

All analyses were performed in STATA 15.0 software, StataCorp LP, College Station, TX, USA. We report in line with the STROBE statement [15].

\section{Results}

Of the 14,302 patients entered into our database, 14,139 were selected for the analysis of whom 10,931 underwent transradial and 3,208 transfemoral catheterization (Fig. 1). 
Fig. 1. Patient flow (in accordance with the STROBE statement).
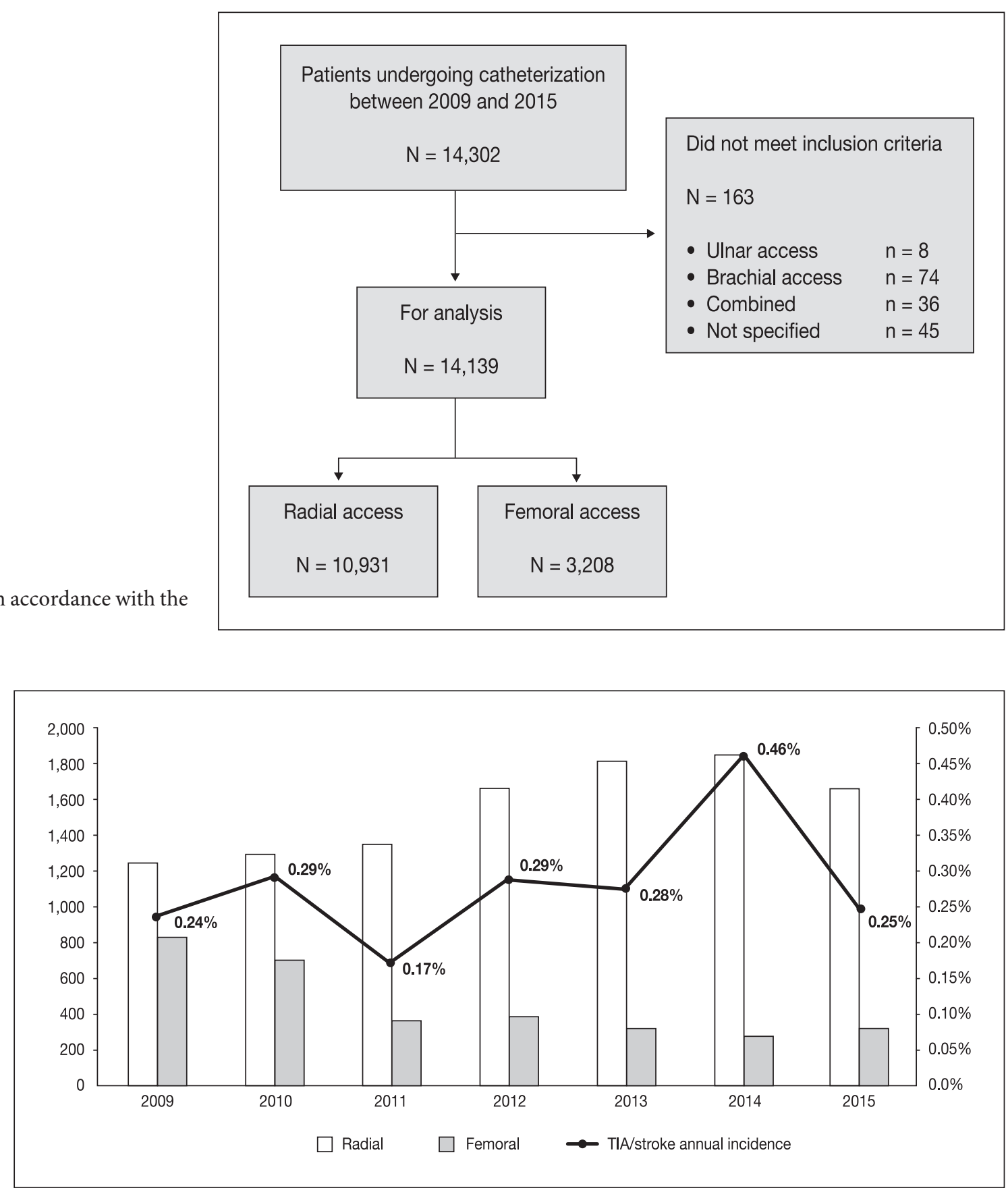

Fig. 2. Proportion of radial and femoral access procedures and annual incidence of TIA/stroke over the study period. Left vertical axis represents numbers of patients; right vertical axis represents the annual incidence of TIA/stroke.

TIA/stroke occurred in $41(0.29 \%)$ patients, of which 40 events were ischemic and 1 hemorrhagic. The median time from catheterization procedure to TIA/stroke development was $40 \mathrm{~min}$ with an interquartile range of $90 \mathrm{~min}$. All the patients with neurological complications under- went computed tomography scan immediately. The clinical outcome of these patients was as follows: $\mathrm{mRS} 5$, severe disability in 1 patient; $\mathrm{mRS} 4$, moderately severe disability in 2 patients; and mRS $0-2$, no symptoms or slight disability in 37 patients. The 30 -day mortality of patients 
Table 1. Differences between baseline characteristics in patients catheterized via radial and femoral accession site

\begin{tabular}{|c|c|c|c|}
\hline & $\begin{array}{l}\text { Transradial group } \\
\text { mean }( \pm \text { SD)/n (\%) }\end{array}$ & $\begin{array}{l}\text { Transfemoral group } \\
\text { mean }( \pm S D) / n(\%)\end{array}$ & $p$ value \\
\hline Number & $10,931(76.5)$ & $3,208(22.4)$ & \\
\hline Reason for admission: ACS & $1,906(17.4)$ & $646(20.1)$ & 0.002 \\
\hline Age & $66.8( \pm 10.5)$ & $67.3( \pm 11.2)$ & 0.016 \\
\hline Male & $6,888(63.0)$ & $2,011(62.7)$ & 0.839 \\
\hline BMI & $29.6( \pm 5.1)$ & $28.3( \pm 10.9)$ & 0.000 \\
\hline \multicolumn{4}{|l|}{ Comorbidity } \\
\hline Hypertension & $9,363(85.7)$ & $2,725(85.0)$ & 0.703 \\
\hline Diabetes & $3,564(32.6)$ & $1,082(33.7)$ & 0.329 \\
\hline Type 2 & $3,411(31.2)$ & $1,022(31.9)$ & 0.560 \\
\hline Type 2 on insulin & $934(8.5)$ & 339 (10.6) & 0.001 \\
\hline Dyslipidemia & $8,072(73.8)$ & $2,484(77.4)$ & 0.039 \\
\hline Smoking (current) & $1,926(17.6)$ & $489(15.2)$ & 0.004 \\
\hline Ex-smoker & $2,771(25.3)$ & $829(25.8)$ & 0.626 \\
\hline COPD & $1,433(13.1)$ & $387(12.1)$ & 0.145 \\
\hline CKD & $910(8.3)$ & $400(12.5)$ & 0.000 \\
\hline Peptic ulcer disease & $1,108(10.1)$ & $369(11.5)$ & 0.037 \\
\hline \multicolumn{4}{|l|}{ Previous cardiovascular disease } \\
\hline Any previous form of CHD & $3,138(28.7)$ & $1,525(47.5)$ & 0.000 \\
\hline ACS & $1,992(18.2)$ & $963(30.0)$ & 0.000 \\
\hline Stable angina & $1,146(10.5)$ & $562(17.5)$ & 0.000 \\
\hline Previous revascularization & $2,270(20.8)$ & $1,286(40.1)$ & 0.000 \\
\hline Previous $\mathrm{PCl}$ & $1,975(18.1)$ & $530(16.5)$ & 0.066 \\
\hline Previous $\mathrm{PCI}+\mathrm{CABG}$ & $109(1.0)$ & $185(5.8)$ & 0.000 \\
\hline Previous CABG & $175(1.6)$ & 565 (17.6) & 0.000 \\
\hline Valvular disease & $999(9.1)$ & $384(12.0)$ & 0.000 \\
\hline Aortal stenosis & $402(3.7)$ & $132(4.1)$ & 0.264 \\
\hline Mitral regurgitation & $383(3.5)$ & $144(4.5)$ & 0.013 \\
\hline History of TIA/stroke/carotid artery stenosis & $987(9.0)$ & $424(13.2)$ & 0.000 \\
\hline Ischemic stroke/TIA & $876(8.0)$ & $372(11.6)$ & 0.000 \\
\hline Hemorrhagic stroke & $28(0.3)$ & $8(0.2)$ & 0.976 \\
\hline Asymptomatic carotid artery stenosis & $80(0.7)$ & $43(1.3)$ & 0.002 \\
\hline \multicolumn{4}{|l|}{ Antiplatelet medication } \\
\hline ASA & 8,627 (78.9) & $2,663(83.0)$ & 0.023 \\
\hline Inhibitors P2Y12 & $4,382(40.1)$ & $1,440(44.9)$ & 0.000 \\
\hline Clopidogrel & $3,718(34.0)$ & $1,179(36.8)$ & 0.021 \\
\hline Ticlopidine & $570(5.2)$ & $245(7.6)$ & 0.000 \\
\hline Other & $94(0.9)$ & $16(0.5)$ & 0.035 \\
\hline \multicolumn{4}{|l|}{ Anticoagulation } \\
\hline LMWH & $1,677(15.3)$ & $446(13.9)$ & 0.063 \\
\hline Warfarin & $479(4.4)$ & $107(3.3)$ & 0.009 \\
\hline NOAC & $97(0.9)$ & $26(0.8)$ & 0.695 \\
\hline
\end{tabular}

There were $3.6 \%$ and $10.9 \%$ missing values of the $\mathrm{BMI}$ in the transradial and transfemoral groups, respectively. In the transfemoral group, $2 \%$ patients did not have information available about the history of TIA/stroke. All remaining data were complete or missed $<0.5 \%$ values. Differences between the transradial and transfemoral groups were tested at $\alpha=0.05$ using the $t$ test or 2 -sided exact significance test. ACS, acute coronary syndrome; $\mathrm{BMI}$, body mass index; $\mathrm{COPD}$, chronic obstructive pulmonary disease; $\mathrm{CHD}$, coronary heart disease; $\mathrm{PCl}$, percutaneous coronary intervention; CABG, coronary artery bypass grafting; ASA, acetylsalicylic acid; LMWH, low-molecularweight heparin; NOAC, novel oral anticoagulants; TIA, transient ischemic attack; CKD, chronic kidney disease. 
Table 2. Differences in outcomes of the catheterization performed via radial and femoral accession site

\begin{tabular}{llll}
\hline & $\begin{array}{l}\text { Transradial group } \\
\text { mean }( \pm \mathrm{SD}) / n(\%)\end{array}$ & $\begin{array}{l}\text { Transfemoral group } \\
\text { mean }( \pm \mathrm{SD}) / n(\%)\end{array}$ & $p$ value \\
\hline Periprocedural TIA/stroke & $31(0.28)$ & $10(0.31)$ & 0.775 \\
Skiascopic time, min & $5.0( \pm 11.3)$ & $5.8( \pm 4.8)$ & 0.000 \\
TIMI major or minor bleeding & $2(0.02)$ & $15(0.47)$ & 0.000 \\
30-day mortality & $64(0.59)$ & $36(1.12)$ & 0.003 \\
1-year mortality & $512(4.68)$ & $204(6.36)$ & 0.003 \\
1-year revascularization & $1,718(15.72)$ & $399(12.44)$ & 0.000 \\
1-year myocardial infarction & $258(2.36)$ & $91(2.84)$ & 0.135 \\
\hline
\end{tabular}

There were $3.2 \%$ and $13.5 \%$ missing values of the sciascopic time in the transradial and transfemoral groups, respectively. Differences between the transradial and transfemoral groups were tested at $\mathrm{a}=0.05$ using the $t$ test or 2-sided exact significance test. TIA, transient ischemic attack; TIMI major bleeding, any intracranial bleeding, clinically overt bleeding with a drop in hemoglobin of $\geq 5 \mathrm{~g} / \mathrm{dL}$; TIMI minor bleeding, clinically overt bleeding resulting in hemoglobin drop of 3 to $<5 \mathrm{~g} /$ day.

with periprocedural TIA/stroke $(1 / 41-2.44 \%)$ and without TIA/stroke $(102 / 14,261-0.72 \%)$ did not differ significantly $(p=0.192)$.

There has been a significant change from predominantly TFA to predominantly radial access during our study with trend analysis showing a significant decrease in the number of transfemoral procedures performed $(p=0.027)$ and increase in transradial procedures $(p=$ $0.038)$, while periprocedural stroke annual incidence remained practically constant ( $p=0.484$ ) (Fig. 2).

Patients were divided into TFA and TRA groups depending on the final vascular access utilized. Demographic, clinical, and procedural characteristics of both groups are presented in Table 1. Periprocedural TIA/stroke occurred in $31 / 10,931(0.28 \%)$ patients in the TRA group and 10/3,208 (0.31\%) in the TFA group, and the difference was not statistically significant. Transradial procedures were less frequently accompanied by bleeding $(0.02 \%$ vs. $0.47 \%, p<0.000)$, and the 30 -day mortality was also lower $(0.59 \%$ vs. $1.12 \%, p=0.003)$ (Table 2$)$.

To eliminate potential confounding, we chose covariates with significant baseline differences between groups and previously known risk factors for periprocedural stroke to predict the occurrence of the periprocedural TIA/stroke using multivariate logistic regression. Age remained the only significant predictor, with each additional year representing an odds ratio $(\mathrm{OR})=1.09$ (CI $1.05-1.13, p<0.000)$. In the multivariate regression, the choice of accession site had no impact on periprocedural TIA/stroke OR $=0.81(0.38-1.75, p=0.592)$ (Fig. 3A).

The same parameters were used to calculate PS as the probability of being catheterized via the radial artery
(Fig. 3B). We also tested the impact of the second-order terms and interactions, but these were not included in the final model. The impact of accession site on the risk of periprocedural stroke was tested using PS-adjusted logistic regression with Firth's correction for rare outcomes, yielding a statistically insignificant estimate $\mathrm{OR}=0.81$ $(0.38-1.72, p=0.577)$.

To cross-validate our result, we employed PS matching using a caliper width of 0.1 . An average treatment effect resulting from 13,338 matches showed no difference in the risk of periprocedural stroke and the accession site $(p=0.664$, details not presented).

\section{Discussion/Conclusion}

Taken together, in our registry cohort of 14,139 catheterizations, we show that the choice of accession site had no impact on the risk of periprocedural TIA/stroke. The result was confirmed in the multivariate regression analysis, PS-adjusted regression analysis, and via PS matching.

While rates of other catheterization complications have declined over the last decade, the periprocedural stroke rate ranges between $0.09 \%$ and $0.3 \%$ and remains constant despite important technical advancement in the field [6]. Thus, periprocedural stroke complicating cardiac catheterization is a very rare event, so absolute differences in their frequency in RT are small and analyses may be underpowered to detect statistically significant differences between TRA and TFA.

The selection of patients to be enrolled in our prospective registry reflects real-life daily practice including diag- 


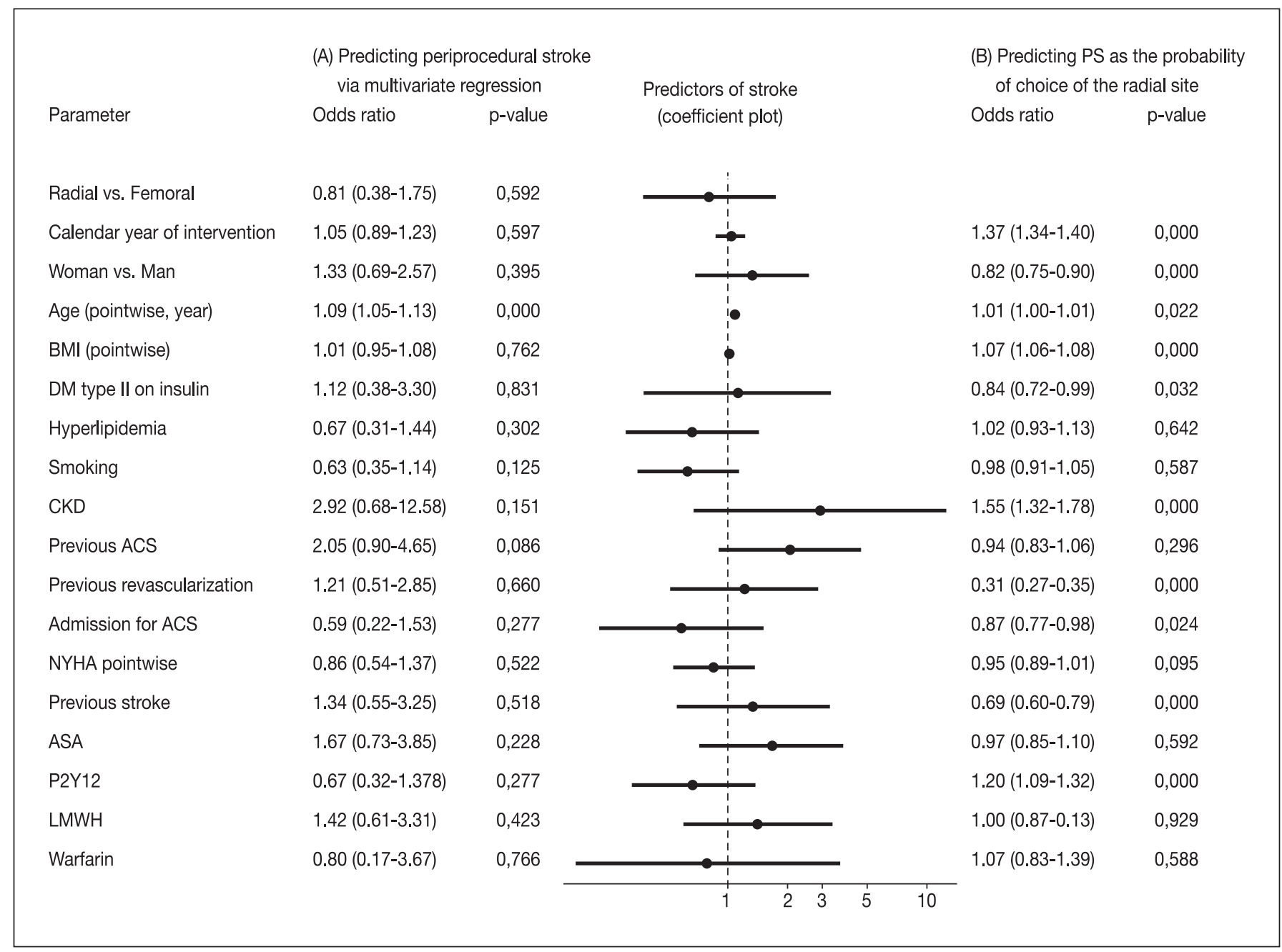

Fig. 3. (A) Coefficients for parameters used to predict stroke. (B) Coefficients for parameters used to predict the propensity score (defined as the probability to be catheterized via radial access). PS, propensity score; BMI, body mass index; DM, diabetes; CKD, chronic kidney disease; ACS, acute coronary syndrome; NYHA, New York Heart Association class; ASA, acetylsalicylic acid; P2Y12, P2Y12 inhibitor use; LMWH, low-molecular-weight heparin use; OR, odds ratio. nostic catheterization and intervention, and patients with acute and stable coronary heart disease, chest pain, valvular disease, heart failure with reduced ejection fraction, and structural heart disease. Sample size, prospective data collection, and validation allowed us to analyze a very rare event (stroke) in relation to the accession site used.

The TIA/stroke rate in our registry was higher than that in the articles published by the British, Portuguese, and Italian groups, and similar to Japanese data [5-8]. Inhospital mortality due to stroke was low and did not differ significantly from groups of patients without stroke.

TFA and TRA groups were balanced at baseline except for body mass index, presence of dyslipidemia, chronic kidney disease, peptic ulcer disease, history of acute coronary syndrome (ACS), previous revascularization, valvular disease, stroke, antithrombotic medication used, and the proportion of active smokers and diabetics on insulin. The operators tended to choose the radial approach in obese patients probably due to concerns of bleeding complications. The femoral approach was preferred in different subgroups of patients: those with chronic kidney disease, where peripheral vascular disease and potential future need for arteriovenous fistula creation could come into consideration; those with previous ACS and revascularization, where a nonpalpable radial artery after a previous procedure and easier bypass graft engagement via a 
femoral approach could play a role; and those with previous stroke, where concerns about higher stroke risk in radial access according to pathophysiologic assumptions and limited evidence then available were raised.

Similar to all reviewed studies, there has been a significant change from predominantly TFA to predominantly radial access during our study. The transition period was long enough to witness experienced transfemoral operators becoming experienced transradial operators.

Age remained the only significant predictor of TIA/ stroke after cardiac catheterization according to the analysis of our registry. This reminds us that cardiac catheterization (even diagnostic) should be planned after thorough risk-benefit assessment in elderly patients.

Results of our robust analysis revealed different results from other observational data focused on the topic. Moreover, inspection of the primary reports of previous trials showed that periprocedural stroke is severely underreported in the primary RT, with only 3 articles presenting the periprocedural events separately [16-18]. The key meta-analysis by Sirker et al. [2] in 2016 included only 2 observational studies and $3 \mathrm{RT}$ reporting neurological complications separately.

In summary, radial access for cardiac catheterization is associated with a significantly lower risk of bleeding, vascular complications, and possibly mortality, mainly in patients with ACSs [19]. The situation is different with regard to periprocedural TIA/stroke, where both accession sites confer similar risk. Despite the increasing use of transradial procedures, large-bore TFA will always be necessary in structural heart interventions, extracorporeal membrane oxygenation support, and complex PCI procedures. Transfemoral way remains the predominant access for diagnostic and interventional procedures in the Unites States [20]. Continuous reexamination of the association between accession site and stroke in more recent observational studies is necessary [21]. Our updated evidence represents important information applicable to common clinical practice and source of data for possible future meta-analyses.

\section{Limitations}

A few limitations of our study should be mentioned. Albeit prospective, the study design was observational with all known general limitations, including unbalanced baseline characteristics of transradial and transfemoral groups and possible confounding related to accession site choice by individual operators. We controlled for all (to us) known confounders using a proper adjustment by both the multivariate analysis and PS. After all, there remains a risk of unmea- sured confounding - an inherent trait of nonrandomized studies. The single-center pattern of an albeit robust sample limited size and power of the estimate.

ACS patients represented approximately one-fifth of our entire cohort. The study sample represented real-life patients admitted or transferred to hospital in stabilized conditions. Patients with non-ST-elevation myocardial infarction with ongoing ischemia, ST-elevation myocardial infarction, or cardiogenic shock were not included in the analysis. Results must be generalized with caution to the entire spectrum of invasive procedures. Some studies have shown that ACS represents an independent predictor of stroke and/or favored transradial approach $[5,7]$. In other studies, such a trend was not detected [8]. There was no significant interaction between subgroups of ACS patients and access site in our data.

The timeframe for identifying periprocedural TIA/ stroke was defined as the time between procedure and hospital discharge. This represents a possible bias in patients who develop TIA/stroke later during hospital course without any casual relation to the catheterization procedure. Regarding a very short time interval between catheterization procedure and TIA/stroke development in our sample, such a bias is less probable. Meanwhile, it is possible that some TIA/strokes with transient symptoms can be missed in sedated patients early after the catheterization procedure.

From the clinician's point of view, we analyzed several potential risk factors for periprocedural TIA/stroke, and age remained the only significant predictor of this complication. Other potentially important factors including burden of atherosclerotic disease in the aorta, experience of the operators, and complexity of procedures may play a significant role. These factors pose challenges for quantification and they are beyond the scope of our analysis.

Our observational estimate compared procedural complications of experienced transfemoral and transradial operators. Contemporary ways of fellow training in interventional cardiology favoring a radial-first approach can lead to low transfemoral expertise and subsequently a higher complication rate already mentioned in the literature $[22,23]$.

\section{Conclusion}

Observational data from a large prospective registry cohort indicate that accession site has no influence on the risk of periprocedural TIA/stroke after cardiac catheterization. 


\section{Acknowledgment}

The authors appreciate the contribution of the Institute of Health Information and Statistics of the Czech Republic (ÚZIS) to long-term follow-up data collection.

\section{Statement of Ethics}

This study was performed in line with the principles of the Declaration of Helsinki. Approval was granted by the Ethical Review Board of the Hospital of Pardubice (Etická komise Pardubické nemocnice) (reference number 626/B/19.6.2020). Each participant provided informed consent to the procedure and data collection.

\section{Conflict of Interest Statement}

J.M. received speaker honoraria from Servier, Novartis, and AstraZeneca. I.V. received speaker honoraria from AstraZeneca, Bayer, Pfizer, Eli Lilly, and Chiesi. V.N. received speaker honoraria from Terumo and Teleflex. M.P. received speaker honoraria from Servier. The other authors have no conflict of interests to declare.

\section{Funding Sources}

The research was supported by a grant (Grant No. IGSFZS_2019_005) from the Faculty of Health Studies, University of Pardubice, Czech Republic.

\section{Author Contributions}

J.M. designed the study, gathered data, and wrote the draft of the manuscript; I.V. gathered data and revised the manuscript for important intellectual content; J.T. wrote the draft of the manuscript and performed the statistical analyses; T.D. performed the statistical analyses and revised the manuscript for important intellectual content; M.B. designed the study and revised the manuscript for important intellectual content; J.P. gathered data; P.G. gathered data and revised the manuscript for important intellectual content; J.V., K.B., J.M., A.S., J.B., V.R., V.N., T.L., and M.P. gathered data; and J.V. and P.V. gathered data and revised the manuscript for important intellectual content.

\section{Data Availability Statement}

The data that support the findings of this study are available in a public repository [24].

\section{References}

1 Patel VG, Brayton KM, Kumbhani DJ, Banerjee S, Brilakis ES. Meta-analysis of stroke after transradial versus transfemoral artery catheterization. Int J Cardiol. 2013 Oct;168(6) $5234-8$.

2 Sirker A, Kwok CS, Kotronias R, Bagur R, Bertrand $\mathrm{O}$, Butler R, et al. Influence of access site choice for cardiac catheterization on risk of adverse neurological events: a systematic review and meta-analysis. Am Heart J. 2016 Nov;181:107-19.

3 Ferrante G, Rao SV, Jüni P, Da Costa BR, Reimers B, Condorelli $\mathrm{G}$, et al. Radial versus femoral access for coronary interventions across the entire spectrum of patients with coronary artery disease: a meta-analysis of randomized trials. JACC Cardiovasc Interv. 2016 Jul;9(14):1419-34.

4 Kolkailah AA, Alreshq RS, Muhammed AM, Zahran ME, Anas El-Wegoud M, Nabhan AF. Transradial versus transfemoral approach for diagnostic coronary angiography and percutaneous coronary intervention in people with coronary artery disease. Cochrane Database Syst Rev. 2018 Apr 18;4(4):CD012318.

5 Shoji S, Kohsaka S, Kumamaru H, Sawano M, Shiraishi Y, Ueda I, et al. Stroke after percutaneous coronary intervention in the era of transradial intervention. Circ Cardiovasc Interv. 2018;11(12):e006761.
6 Pristipino C, Trani C, Nazzaro MS, Berni A, Patti G, Patrizi R, et al. Major improvement of percutaneous cardiovascular procedure outcomes with radial artery catheterisation: results from the PREVAIL study. Heart. 2009 Mar 15;95(6):476-82.

7 Ratib K, Mamas MA, Routledge HC, Ludman PF, Fraser D, Nolan J. Influence of access site choice on incidence of neurologic complications after percutaneous coronary intervention. Am Heart J. 2013 Mar; 165(3):317-24.

8 Raposo L, Madeira S, Teles RC, Santos M, Gabriel HM, Gonçalves P, et al. Neurologic complications after transradial or transfemoral approach for diagnostic and interventional cardiac catheterization: a propensity score analysis of 16,710 cases from a single centre prospective registry-transradial approach and neurologic complications. Cathet Cardiovasc Intervent. 2015 Jul;86(1):61-70.

9 Juliane J. The impact of different techniques used for coronary angiography and percutaneous coronary intervention on the occurrence of procedure-related ischemic cerebral complications [Internet]. [cited 2020 Sep 29]. Available from: https://openarchive.ki.se/ xmlui/handle/10616/45020.

10 Banks JL, Marotta CA. Outcomes validity and reliability of the modified rankin scale: Implications for stroke clinical trials: a literature review and synthesis. Stroke. 2007;38(3): 1091-6.
11 Dattani A, Au L, Tay KH, Davey P. Contrastinduced encephalopathy following coronary angiography with no radiological features: a case report and literature review. Cardiology. 2018;139(3):197-201.

12 Neumann FJ, Sousa-Uva M, Ahlsson A, Alfonso F, Banning AP, Benedetto U, et al. [2018 ESC/EACTS Guidelines on myocardial revascularization. The Task Force on myocardial revascularization of the European Society of Cardiology (ESC) and European Association for Cardio-Thoracic Surgery (EACTS)]. G Ital Cardiol. 2019;20(2):1S-61S.

13 Firth D. Bias reduction of maximum likelihood estimates. Biometrika. 1993;80(1):27.

14 Coveney J. FIRTHLOGIT: Stata module to calculate bias reduction in logistic regression [Internet]. Stat Softw Components. [cited 2020 Sep 29]. Available from: https://ideas. repec.org/c/boc/bocode/s456948.html.

15 von Elm E, Altman DG, Egger M, Pocock SJ Gøtzsche PC, Vandenbroucke JP. The Strengthening the Reporting of Observational Studies in Epidemiology (STROBE) statement: guidelines for reporting observational studies. J Clin Epidemiol. 2008 Apr;61(4): 344-9.

16 Cooper CJ, El-Shiekh RA, Cohen DJ, Blaesing L, Burket MW, Basu A, et al. Effect of transradial access on quality of life and cost of cardiac catheterization: a randomized comparison. Am Heart J. 1999 Sep;138(3):430-6. 
17 Brueck M, Bandorski D, Kramer W, Wieczorek M, Höltgen R, Tillmanns H. A randomized comparison of transradial versus transfemoral approach for coronary angiography and angioplasty. JACC Cardiovasc Interv. 2009 Nov;2(11):1047-54

18 Bernat I, Horak D, Stasek J, Mates M, Pesek J, Ostadal P, et al. ST-segment elevation myocardial infarction treated by radial or femoral approach in a multicenter randomized clinical trial: the STEMI-RADIAL trial. J Am Coll Cardiol. 2014 Mar;63(10):964-72.

19 Mason PJ, Shah B, Tamis-Holland JE, Bittl JA, Cohen MG, Safirstein J, et al. An update on radial artery access and best practices for transradial coronary angiography and intervention in acute coronary syndrome: a scientific statement from the American Heart Association. Circ Cardiovasc Interv. 2018;11(9): e000035.

20 Damluji AA, Nelson DW, Valgimigli M, Windecker S, Byrne RA, Cohen F, et al. Transfemoral approach for coronary angiography and intervention: a collaboration of international cardiovascular societies. JACC Cardiovasc Interv. 2017 Nov;10(22):226979.

21 Lin CF, Chang YH, Chi NF, Chen II, Liu HY, Chien LN. Percutaneous coronary intervention in patients hospitalized for non-ST-elevation myocardial infarction and the risk of postdischarge ischemic stroke at 6-month, 1-year, and 3-year follow-ups. Heart Vessels. 2019 Jul;34(7):1132-9.
22 Hamon M, Pristipino C, Di Mario C, Nolan J, Ludwig J, Tubaro M, et al. Consensus document on the radial approach in percutaneous cardiovascular interventions: position paper by the European Association of Percutaneous Cardiovascular Interventions and Working Groups on Acute Cardiac Care** and Thrombosis of the European Society of Cardiology. EuroIntervention. 2013 Mar;8(11):1242-51.

23 Blake SR, Shahzad A, Aggarwal SK, Kumar A, Khan A, Stables RH. Radial versus femoral vascular access in ST-elevation myocardial infarction: are the results of femoral operators unfairly represented in observational research? Am Heart J. 2019 Apr;210:81-7.

24 Available from: https://figshare.com/s/ b8d3b60762636fdd0c6d. 